\title{
La política social de la cuarta transformación en México. Un balance del primer año de gobierno de López Obrador
}

\author{
Social policy in Mexico's Fourth Transformation. \\ An assessment of López Obrador's first year in office
}

\author{
MANUEL I. MARTÍNEZ ESPINOZA \\ Centro de Estudios Superiores de México y Centroamérica de la Universidad de Ciencias \\ y Artes de Chiapas (CESMECA-UNICACH)
}

\section{Cómo citar/Citation}

Martínez Espinoza, M. I. (2021). La política social de la cuarta transformación en México. Un balance del primer año de gobierno de López Obrador. Revista Española de Ciencia Política, 55, 121-142. Doi: https://doi.org/10.21308/recp.55.05

\section{Resumen}

Tras el triunfo de Andrés Manuel López Obrador (AMLO) en las elecciones presidenciales de 2018 se generaron altas expectativas sobre la presidencia, particularmente relacionadas con la lucha contra la pobreza y la provisión de bienestar social en México. Para ofrecer unas proyecciones iniciales que permitan evaluar su gestión, esta nota de investigación analiza la política social del autonombrado Gobierno de la Cuarta Transformación durante su primer ańo de vigencia. Se concluye que durante 2019 la política social en México se enfocó en el aumento de recursos para atender espacios marginados y grupos vulnerables. Sin embargo, tales esfuerzos pueden ser infructuosos para combatir eficazmente la pobreza y remontar las falencias conceptuales, estratégicas, institucionales y operativas de la propia política social en el país, y en cambio pueden profundizar su uso como instrumento de clientelismo político.

Palabras clave: política social, bienestar social, programas sociales, pobreza, Gobierno federal, Andrés Manuel López Obrador.

\begin{abstract}
After Andrés Manuel López Obrador (AMLO)'s triumph in the 2018 presidential elections, high expectations emerged about his presidency, particularly in relation to the fight against poverty and the provision of social welfare in Mexico. In order to offer some initial results that
\end{abstract}


would allow us evaluating his management, this research note analyzes the social policy of the self-defined "Government of the Fourth Transformation» during its first year in office.

The research note concludes that during 2019 the social policy in Mexico was focused on increasing resources to attend to marginalized spaces and vulnerable groups. However, those efforts may become unsuccessful in effectively combating poverty and overcoming the conceptual, strategic, institutional and operational shortcomings of the actual social policy in the country; whereas they may deepen its use as an instrument for political patronage.

Keywords: social policy, social welfare, social programs, poverty, Federal Government, Andrés Manuel López Obrador.

\section{INTRODUCCIÓN}

El 1 de julio de 2018 se celebraron elecciones en México para la renovación de 3406 cargos públicos, entre los cuales se encontraba el de presidente de la república. En dichos comicios, Andrés Manuel López Obrador (AMLO), de la coalición Juntos Haremos Historia, conformada por el partido Movimiento de Regeneración Nacional (MORENA), el Partido del Trabajo (PT) y el Partido Encuentro Social (PES), resultó elegido con el $53,19 \%$ de los votos; es decir, con 30110327 de los 56601874 de los sufragios emitidos 1 . Con esos resultados, López Obrador se convirtió en el presidente electo con el mayor apoyo, tanto en número de votos como en términos porcentuales desde Carlos Salinas de Gortari, que fue elegido en 1988 con el 50,3\% de los votos emitidos.

Una vez consumado su triunfo, AMLO aseveró que su gestión conllevaría un cambio profundo y radical en el país, que catalogó como «la Cuarta Transformación de la vida pública de México" (4T), proceso en el cual se renovaría el país porque acabaría con la corrupción y la impunidad, ejercería el presupuesto público con austeridad, aboliría el neoliberalismo y, sobre todo, daría prioridad a los pobres. En sus palabras pronunciadas en su toma de protesta el 1 de diciembre de 2018, afirmó: «Por el bien de todos, primero los pobres. Nuestra consigna de siempre es, a partir de hoy, principio de gobierno»².

Las expectativas sobre la gestión del AMLO son altas, particularmente en los temas de lucha contra la pobreza y bienestar social. Por tanto, una vez transcurrido su primer año de gobierno la pregunta es inevitable: ¿la $4 \mathrm{~T}$ es solo un apelativo asignado por el propio presidente de la república a su gobierno o se proyecta como un viraje en la

1. Según los datos del Instituto Nacional Electoral, «Sistema de consulta de la estadística de las elecciones del proceso electoral 2017-2018». Disponible en: https://siceen.ine.mx:3000/\#/ tablas-resultados [acceso: 15 de marzo de 2020].

2. «Discurso completo del C. presidente Andrés Manuel López Obrador en la toma de protesta». Secretaría de Relaciones Exteriores. Disponible en: https:/embamex.sre.gob.mx/sudafrica/ index.php/discurso-integro-de-andres-manuel-lopez-obrador-al-rendir-protesta-como-presidente [acceso: 21 de febrero de 2021]. 
política social mexicana, factible de incidir en una drástica disminución de la pobreza junto con un incremento en los niveles de bienestar social? Derivado de un proyecto de investigación en marcha, el objetivo de este texto es compartir los hallazgos sobre los planteamientos, dinámicas e itinerarios de la política social de la $4 \mathrm{~T}$ a partir de una evaluación programática del primer año de gobierno de AMLO. Para ello, el artículo se divide en tres apartados: Con el fin de establecer referentes para la evaluación, el primer apartado ofrece la radiografía del régimen de política social en México distinguiendo las instituciones y orientaciones que configuran su andamiaje y sus resultados. El segundo apartado ofrece el análisis pormenorizado de las concepciones, instituciones y acciones de política social durante el primer año de gobierno de AMLO para, en el último apartado, contrastar los hallazgos con los sesgos, vacíos e insolvencias del régimen de política social mexicano para presentar una evaluación global y plantear unas proyecciones en torno la pregunta planteada.

\section{EL RÉGIMEN DE POLÍTICA SOCIAL EN MÉXICO}

Como se ha asentado en la bibliografía especializada, la política social no versa únicamente sobre programas para atender la pobreza ${ }^{3}$, sino que su alcance es más extenso. En una definición connotativa, política social puede entenderse como el entramado institucional de postulados epistemológicos y metodológicos que se despliegan en leyes, organismos, planes y recursos diversos (humanos, financieros, tecnológicos, etc.) con el objetivo prioritario de atender las cuestiones inherentes al bienestar de los distintos segmentos de la población, pero que también incluye metas relacionadas con la estabilidad del sistema político y las correcciones a las ineficiencias del sistema económico ${ }^{4}$.

3. La pobreza es un concepto que remite a significados vinculados a carencias o privaciones inaceptables de condiciones materiales, económicas o sociales para la vida (Spicker, 2009: 302). Aunque su médula semántica gravita en torno a las privaciones materiales, la pobreza es provocada por múltiples factores, tales como el crecimiento económico, las políticas económica, fiscal o industrial, el mercado de trabajo, el sistema político, la corrupción y hasta la geografía, por mencionar algunos de los que se han señalado por la literatura especializada. Se trata, por tanto, de un fenómeno multicausal. Por ello, la medición oficial de la pobreza en México sigue el criterio de la multidimensionalidad, es decir, se define a una persona en situación de pobreza cuando tiene al menos una de las seis carencias sociales identificadas (rezago educativo, acceso a los servicios de salud, acceso a la seguridad social, calidad y espacios en la vivienda, acceso a los servicios básicos en la vivienda y acceso a la alimentación) y su ingreso es insuficiente para adquirir los bienes y servicios contemplados en la canasta alimentaria y no alimentaria. Para conocer más en detalle la medición de la pobreza en México, consúltese CONEVAL (2010).

4. Para profundizar en el análisis del concepto de política social, se sugiere revisar la siguiente bibliografía: Herrera y Castón (2003); Martínez Espinoza (2019); Molina (2004), y Montagut (2000). 
Como lo formuló Jennifer Pribble (2011), cuando ese entramado funciona como un sistema de concepciones, instrumentaciones e implementaciones, se puede denominar como un régimen de política social. El concepto de régimen de política social es apropiado, tanto contextual como metodológicamente, para identificar el paquete de políticas de protección social y combate a la pobreza en América Latina. Y ello es así por un lado porque en la región no hay un modelo homogéneo de Estado de bienestar del tipo de los países desarrollados (Antía, 2018: 199-200), y por otro porque el término permite abordar la compleja trama de interacciones que establece el Estado con la sociedad, antes que la trama de interacciones entre esferas (Martínez Franzoni, 2008: 35).

En el caso de México se pueden identificar inercias, modos y esquemas que, construidos, preservados y ahondados históricamente, permiten asegurar que ostenta un tipo de régimen de política social con fundamentos que estructuran su funcionamiento. Dicho régimen de política social en México tiene su elemento fundacional en la Constitución política promulgada en 1917, donde se reconoció la salud, la educación y la seguridad social como derechos sociales básicos que los poderes públicos tenían la obligación de hacer válidos, por lo que es «mediante este marco normativo-institucional que se fundan las bases de una estructura formal para impulsar el desarrollo social bajo responsabilidad estatal» (Valverde, 2015: 106).

Ese fundamento legal y normativo sustentó la instauración del régimen de política social posrevolucionario que, en correspondencia con el contexto de su creación, se aglutinó a un modelo de nación y a instituciones políticas nacientes, de manera que la política social en su formación coadyuvó también a los rendimientos políticos, sociales y económicos de las clases gobernantes.

Gracias a esa dinámica, el régimen de política social mexicano incluyó y extendió cuatro condiciones que han determinado su desempeño y resultados. La primera condición es que las instituciones fundantes adoptaron el enfoque de desarrollo prevaleciente en la época de la segunda posguerra en la región, el cual concebía que el modelo de industrialización por sustitución de importaciones (ISI) resultaba suficiente para el bienestar de la población. La idea central era que dicho modelo aportaría mercado, infraestructura y empleos, por lo que las demás instituciones tendrían que apoyarlo. Esta noción derivó en el entendimiento de la política social como paliativo de las políticas económica, financiera y hasta laboral. Por ello, desde su origen, las instituciones y programas del ámbito del desarrollo social se supeditaron al paradigma económico (Torres y Rojas, 2015).

A partir de ese condicionamiento central donde la política social respaldó el proyecto de industrialización (Barba, 2016), las estrategias, instituciones y programas sociales se centraron en los grupos que apoyaron el proyecto económico del régimen político, por lo que los beneficios sociales - a excepción de la educación- se vincularon al trabajo asalariado (Gabarrot, 2012: 38). Esto ocasionó que se excluyeran a los segmentos que no cumplían con dicha condición: mujeres y hombres pobres en el ámbito urbano con trabajos informales, gente del campo e indígenas (Barba, 2007). 
Así, la edificación de la protección social en México no se «relacionó con la categoría de ciudadano, sino de empleado» (Dautrey, 2013: 31).

La tercera condición fue su alineamiento con el sistema político, pues los beneficios sociales fueron distribuidos privilegiando a los sectores organizados que coadyuvaban a la estabilidad del régimen político (partido político hegemónico, sindicatos y confederaciones oficiales), con lo que se generó un "pacto de dominación» (Brachet-Márquez, 1996). De esta forma, las instituciones públicas de desarrollo social fueron «el soporte ideológico y material de legitimidad de los gobiernos» (Moreno et al., 2004: 61). Dada su lógica de intercambio clientelar con grandes grupos, el régimen de política social ha sido incluso clasificado como de "corporativismo estratificado» (Bizberg, 2012).

El cuarto condicionamiento fue la deficiente planeación, especialización y articulación de las numerosas acciones de política social, lo que se evidencia en que en muchos casos «primero se desarrollaron las instituciones y después se codificaron los derechos» (Valencia et al., 2012: 12). Así, las políticas sociales en el periodo posrevolucionario tuvieron un tratamiento prescriptivo; es decir, «sin la especialización de la planeación, la presupuestación y la gestión» (Moreno et al., 2004: 57) necesarias para conformar un régimen de política social integral.

A mediados de la década de 1970, se produjo en México una grave crisis económica que provocó que colapsaran los niveles de bienestar y el número de pobres se incrementara drásticamente. Simultáneamente, comenzó a estar en boga un modelo de Estado mínimo donde este se disciplina fiscalmente, reduce sus órganos administrativos, se descentraliza y externaliza sus responsabilidades hacia los sectores privados y sociales. En ese escenario - denominado neoliberal — la política social enfatiza su objetivo de corregir las ineficiencias del sistema económico. Es decir, en el marco de estas adecuaciones de concepción y operación del Estado, la política social adopta un modelo que se ha identificado como residual, es decir, aquel donde el Estado deja la función de protección social a las "comunidades naturales» (familia, comunidad, empresas) y solo interviene de manera mínima y temporal cuando dichas comunidades fallan (Titmuss, 1981).

Con el acaecimiento de dicho modelo, los regímenes de bienestar en América Latina tendieron a la residualización: al asumir como su eje el respeto al libre juego del mercado, las prestaciones públicas se orientarían únicamente a corregir externalidades de la economía y no intentarían modificar la estructura social generada por el libre curso de la oferta y la demanda porque reconocerían que la pobreza procede de limitaciones individuales y que por ello solo hay que proteger transitoriamente a los más pobres incapaces de ayudarse a sí mismos, cuando están dispuestos a reincorporarse al mercado laboral (Barba, 2007: 15).

En ese momento, en México se originó un cambio en las orientaciones y uso de recursos de la política social, que tuvo como principales efectos «la eliminación de la mayoría de los subsidios generalizados que se habían utilizado en apoyo de la producción (fertilizantes, créditos, electricidad, semillas, etc.) y el consumo de alimentos básicos» (Ordóñez, 2018: 380). También comienzan a implementarse programas para atender de manera directa y focalizada a la población en condiciones de pobreza, sobre todo mediante transferencias 
monetarias 5 . Ello significó un cambio relevante, pues «aunque resulte un tanto paradójico, hasta antes de 1982 la política social no tuvo el sustento de un programa de carácter nacional, universal y ampliamente incluyente de las poblaciones desfavorecidas» (Castillo y Arzate, 2013: 72). A partir de entonces, la política social en el país «se transformó en una política orientada a atender las necesidades específicas de un grupo social determinado en lugar de dar apoyos generalizados a toda la población» (Cejudo y Michel, 2015: 38).

Como se muestra en el cuadro 1, el porcentaje de pobres no parece tener correlación con la existencia o ausencia de algún programa de lucha contra la pobreza, sino más bien con los sobresaltos macroeconómicos, como fueron la crisis de 1995 y la desaceleración mundial del periodo 2008-2010, donde el número de personas en situación de pobreza incrementó. Por lo tanto, es factible afirmar que la estrategia de lucha contra la pobreza mediante programas focalizados no ha erradicado ni reducido la pobreza; más bien ha funcionado como factor de contención de las convulsiones económicas, pues sin estos programas «las desigualdades y los efectos sociales de la crisis hubieran sido más devastadores» (Ordóńez, 2017: 132). Tal afirmación es incluso avalada por el organismo oficial para la medición de la pobreza, que aseguró que a pesar del repunte en el número de pobres entre 2006 y 2008, sin la existencia de estos programas, la pobreza alimentaria hubiese sido mayor que la que se registró (CONEVAL, 2009: 14).

Los programas sociales no son condición suficiente para la erradicación de la pobreza, pero podrían haber conseguido resultados más contundentes y consistentes. Ello se debe a las anomalías que han mostrado. En primer lugar, los programas sociales se han diseñado e implementado de manera fragmentada, pues cada nivel de gobierno cuenta con sus propios programas ${ }^{6}$, con lo que suelen duplicarse, estorbarse y dispersar los recursos públicos. Por ejemplo, en 2018 el CONEVAL identificó 150 programas, de los cuales 58 (el 38,6\% del total) estaban duplicados (CONEVAL, 2018a: 169). Entre 2016 y 2018, el Gobierno federal gastó más de un billón de pesos en programas repetidos (Rodríguez y Nácar, 2018). La duplicidad entre niveles de gobierno conlleva otra insuficiencia, pues el 97,6\% de los programas han sido diseñados e implementados por los estados y municipios ${ }^{7}$, pero las capacidades institucionales de los Gobiernos

5. Los programas de transferencias monetarias condicionadas (PTC) han sido los instrumentos arquetípicos de intervención focalizada contra la pobreza en América Latina desde mediados de la década de 1990. Los PTC tienen dos características básicas: a) la entrega periódica de recursos monetarios a los beneficiarios con la condición de que b) estos cumplan con ciertos condicionamientos para mantener dichos beneficios. Los PTC se iniciaron en Brasil en 1995 en tres ciudades y a nivel nacional en México con el Programa de Educación, Salud y Alimentación. Desde entonces, los PTC se extendieron «como la pólvora por toda América Latina y más tarde en el resto del mundo» (Banerjee y Duflo, 2014: 111).

6. Por ejemplo, en 2018 el Consejo Nacional de Evaluación de la Política de Desarrollo social (CONEVAL) identificó 6489 programas y acciones de desarrollo social distribuidas entre los niveles federal (150 programas), estatal (2528) y municipal (3811).

7. Fuente: Inventario nacional CONEVAL de programas y acciones de desarrollo social. Disponible en: https://cutt.ly/cln5RS4 [acceso: 7 de febrero de 2020]. 
Cuadro 1.

PobreZa y programas SOCIALES MÁs RELEVANTES EN MÉXico (I977-20 I 8)

\begin{tabular}{cccc}
\hline Año & $\begin{array}{c}\text { Población } \\
\text { pobre en } \\
\text { México (\%) }\end{array}$ & $\begin{array}{c}\text { Población pobre } \\
\text { en México } \\
\text { (millones) }\end{array}$ & Programa social más relevante \\
\hline 1977 & 63.8 & 40 & PIDER, COPLAMAR \\
\hline 1984 & 53 & 39.8 & PIDER, COPLAMAR, SAM \\
\hline 1989 & 53.5 & 44.7 & PRONASOL \\
\hline 1992 & 53.1 & 46.7 & PRONASOL \\
\hline 1994 & 52.4 & 51.2 & PRONASOL \\
\hline 1996 & 69 & 66.2 & PRONASOL \\
\hline 1998 & 63.7 & 62.6 & PROGRESA-OPORTUNIDADES-PROSPERA \\
\hline 2000 & 53.6 & 54 & PROGRESA-OPORTUNIDADES-PROSPERA \\
\hline 2002 & 50 & 52.1 & PROGRESA-OPORTUNIDADES-PROSPERA \\
\hline 2004 & 47.2 & 49.6 & PROGRESA-OPORTUNIDADES-PROSPERA \\
\hline 2005 & 47 & 48.9 & PROGRESA-OPORTUNIDADES-PROSPERA \\
\hline 2006 & 42.9 & 46.5 & PROGRESA-OPORTUNIDADES-PROSPERA \\
\hline 2008 & 44.4 & 49.4 & PROGRESA-OPORTUNIDADES-PROSPERA \\
\hline 2010 & 46.1 & 52.8 & PROGRESA-OPORTUNIDADES-PROSPERA \\
\hline 2012 & 45.4 & 53.3 & PROGRESA-OPORTUNIDADES-PROSPERA \\
\hline 2014 & 46.2 & 55.3 & PROGRESA-OPORTUNIDADES-PROSPERA \\
\hline 2016 & 43.6 & 53.4 & PROGRESA-OPORTUNIDADES-PROSPERA \\
\hline 2018 & 41.9 & 52.4 & PROGRESA-OPORTUNIDADES-PROSPERA \\
\hline
\end{tabular}

PIDER. Programa de Inversiones para el Desarrollo Rural (1973-1982).

COPLAMAR. Coordinación General del Plan Nacional de Zonas Deprimidas y Grupos Marginados (1976-1982).

SAM. Sistema Alimentario Mexicano (1980-1983).

PRONASOL. Programa Nacional de Solidaridad (1988-1995).

PROGRESA. Programa de Educación, Salud y Alimentación (se inició en 1997 y cambió de nombre a Oportunidades en 2002).

OPORTUNIDADES. Programa de Desarrollo Humano «Oportunidades» (se inició en 2002 y cambió de nombre en 2014). PROSPERA. Programa de Inclusión Social (se inició en 2014 y fue cancelado en 2019).

Fuente: elaboración propia con datos obtenidos para el periodo 1977-1989 de Székely (2005); para el periodo 1992 2006 de «Evolución de las dimensiones de la pobreza» de CONEVAL, disponible en: https://cutt.ly/gln9YUp [acceso: 17 de marzo de 2020], y para el periodo 2008-2018 de CONEVAL (2019a). De 1977 a 2006 los datos se refieren a la pobreza de patrimonio (insuficiencia del ingreso disponible para adquirir la canasta alimentaria y efectuar los gastos necesarios en salud, educación, vestido, vivienda y transporte, aún si se hiciera uso de todo el ingreso disponible en el hogar exclusivamente para la adquisición de estos bienes y servicios). De 2008 a 2018 los datos se refieren a la población total considerada como pobre por el CONEVAL.

subnacionales para desarrollar una política social eficiente, transparente y participativa son menores que las del Gobierno federal (IPRO, 2018). Por ejemplo, solo en doce entidades el $50 \%$ de sus Gobiernos municipales tienen capacidades altas o muy altas para impulsar el desarrollo sostenible (PNUD, 2019). 
En términos de enfoque, los programas sociales han tendido al asistencialismo, pues han buscado cubrir carencias en lugar de ampliar y salvaguardar los derechos sociales, siguiendo la tendencia de la política social mexicana de centrarse en los indicadores de pobreza (CONEVAL, 2016: 56).

En términos de diseño, los programas sociales en México no suelen tener un enfoque de resultados; es decir, no identifican a su población objetivo ni el cambio que buscan lograr. Así lo constató el CONEVAL en su Informe de enfoque de resultados 2017, donde registró que 88 de los 149 programas sociales federales (59\% del total) no tenían identificado el resultado que pretendían alcanzar (CONEVAL, 2017a: 5). Asimismo, los programas sociales han tendido a la opacidad y al bajo nivel de rendición de cuentas. Por ejemplo, en el Inventario federal de programas y acciones de desarrollo social 2016-2017 se observó que solo un 55\% de los programas federales reportaron contar con un padrón de beneficiarios (CONEVAL, 2017b: 25). Un estudio de una organización de la sociedad civil concluyó que el promedio de programas implementados en condiciones de opacidad entre 2012 y 2016 fue de 24,9\% (GESOC, 2017: 39). Esta opacidad crea entornos propicios para la corrupción, por lo que los programas sociales han sido espacios e instrumentos de clientelismo político, que se ha desplegado en acciones para la compra y coacción del voto, ya sea ofreciendo los servicios y beneficios o condicionando los programas a cambio del apoyo electoral (Hevia, 2010: 121).

En términos presupuestarios, los programas para la superación de la pobreza pasaron de ejecutar un monto de 61 126,6 millones de pesos en el año 2000 -lo que representaba el 0,91\% del PIB de ese año- a ejecutar un presupuesto de 340 964,4 millones de pesos en 2017 - lo que significaba el 1,56\% del PIB de ese año-. Sin embargo, tales aumentos presupuestarios no tuvieron grandes impactos en la cobertura ${ }^{8}$. Por ejemplo, el Progresa-Oportunidades-Prospera (POP) ha sido el programa contra la pobreza de más larga duración en el país y el de mayor alcance en términos de cobertura. En su comienzo en 1997, el POP cubría a 300000 familias, mientras que veinte años después su cobertura alcanzaba a 6,4 millones de familias (Ordóñez y Silva, 2019: 97). Esto significaba que en 2017 el POP dada cobertura a 26,6 millones de personas que, según la medición del CONEVAL, representaba solo el $51 \%$ de personas en situación de pobreza. En un estudio sobre la distribución geográfica y los beneficiarios de las transferencias sociales en 2018, se observó que los municipios con mayor pobreza no son los que tienen mayor cobertura, entre los que destaca el caso de Chiapas «con el menor número de programas sociales por persona en pobreza, y Chiapas es el estado con el mayor porcentaje de pobreza en el país» (Campos, et al., 2018: 18).

8. Los datos del presupuesto de los programas para la superación de la pobreza fueron tomados del cuadro «Gasto del Gobierno Federal ejercido en Programas para la Superación de la Pobreza» correspondiente a los anexos del Sexto informe de Gobierno de Enrique Peña Nieto, disponibles en: https://datos.gob.mx/busca/dataset/sexto-informe-de-gobierno (Meta 2 "México Incluyente», gráfica M02_131). El cálculo del PIB fue realizado con cifras del Centro de Estudios de las Finanzas Públicas, disponibles en: https://www.cefp.gob.mx/ixDOCs/2017/211-PIB.pdf [acceso: 19 de febrero de 2020]. 
Lo anterior puede explicar su constante deficiencia, pues como ha venido informando el CONEVAL, el $38 \%$ de los programas sociales federales no eran prioritarios por su nula aportación para la superación de la pobreza en 2018 (CONEVAL, 2019b: 7). Asimismo, en 2017 los programas no prioritarios fueron el $40 \%$ del total de los programas sociales federales (CONEVAL, 2018b: 225), proporción que en 2016 correspondió al $45 \%$ de los programas, pues no estaban vinculados al ejercicio de los derechos sociales y no contribuían a la disminución de las carencias sociales ni al bienestar económico (CONEVAL, 2016: 46). Todo lo expuesto permite concluir, como se sintetiza en el diagrama 1, que el régimen de política social en México se caracterizó entre 1917 y 2018 por falencias conceptuales, estratégicas, institucionales y operativas que sustentaron su poca eficiencia para proveer el bienestar social y combatir la pobreza, su dispendio de los recursos públicos y su uso como instrumento de clientelismo político. En estas condiciones México inició en 2018 un nuevo Gobierno que ha creado altas expectativas. En el siguiente apartado se analizan sus acciones y resultados en términos de política social durante su primer año de gestión.

Diagrama 1.

Caracterización del régimen de pOlítica social en MÉXico

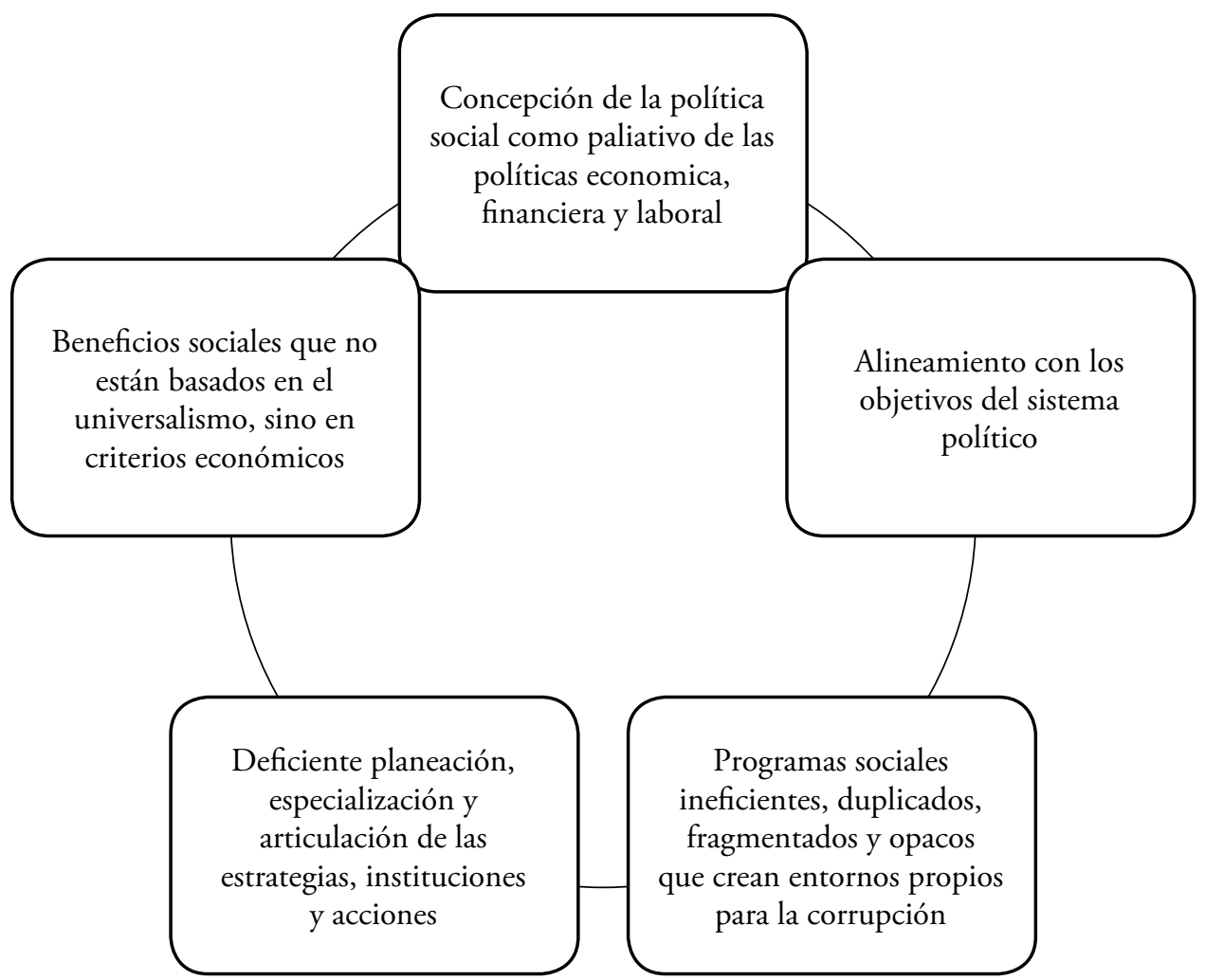

Fuente: elaboración propia. 


\section{UN AÑO DE POLÍTICA SOCIAL EN LA 4T}

El 1 de diciembre de 2018 AMLO tomó posesión como presidente de México. En ese año, según cifras del CONEVAL, el 41,9\% de la población mexicana era considerada pobre. Según información de otros organismos como el Consejo de Evaluación del Desarrollo Social de la Ciudad de México, que en sus mediciones aumenta los umbrales de ingresos e incluye otras variables además de las del CONEVAL, la pobreza en el país alcanzó al $72 \%$ de la población total (EVALÚA, 2019). Además, el antecedente inmediato de la política social federal se caracterizó por la falta de rumbo claro en las estrategias, la ineficiencia para el alcance de objetivos y el desfalco de los recursos públicos.

De esta forma, el desafío para combatir la pobreza e implementar una política social integral sería mayúsculo para el Gobierno federal del periodo 2018-2024. En su primer año de ejercicio, el Gobierno de la $4 \mathrm{~T}$ realizó diversas acciones que ofrecen insumos para un análisis minucioso de sus estrategias de desarrollo social y su talante de política social. En una de sus acciones iniciales más destacadas, el 17 de diciembre de 2018 el presidente López Obrador anunció un aumento del salario mínimo de $16,21 \%$ para garantizar «el bienestar de las trabajadoras y los trabajadores mexicanos», pues con esa medida "van a mejorar los ingresos y aumentar el consumo». Dado que la pérdida del poder adquisitivo del salario mínimo había sido enorme, añadió que «hay quienes sostienen que se perdió el $70 \%$ en los últimos 30 ańos, el Banco de México reconoce una pérdida de $60 \%$, por eso hoy estamos en una nueva etapa» ${ }^{9}$. El aumento al salario mínimo fue un acto relevante de política social por tener un impacto inmediato en los ingresos y pretender asociar - al menos discursivamentela política de bienestar social con el ingreso laboral. Sin embargo, las consecuencias de dicha decisión deben matizarse. En primer lugar, se trata de un incremento porcentual real del $11,11 \%$, no del $16,21 \%$ respecto del año anterior, como el mismo presidente reconoció en una tabla que expuso en sus conferencias matutinas ${ }^{10}$.

Por su parte, el consumo interno se incrementó el 0,9\% en el año 2019, cifra que es baja en comparación con los años previos, en los que los crecimientos interanuales fueron de 4,3\% (2016), 3,2\% (2017) y 2,5 (2018) $)^{11}$. Aunque las cifras de consumo interno ya venían decreciendo y no dependen únicamente del salario mínimo, ha resultado evidente que el aumento al salario mínimo en 2019 no conllevó de forma directa e inmediata un aumento del consumo interno, como afirmó el presidente.

9. Ver: «A partir de enero, el salario mínimo será de 102,68 pesos y en la frontera de 176,72 », Animal Político, 17 de diciembre de 2018. Disponible en: https://cutt.ly/Flme429 [acceso: 24 de enero de 2019].

10. Fuente: «Porcentaje de aumento del salario mínimo nominal y real (1989-2019)». Disponible en: https://cutt.ly/wzZUkf9 [acceso: 8 de febrero de 2019].

11. Fuente: Instituto Nacional de Estadística y Geografía. Consumo privado en el mercado interior. Disponible en: https://www.inegi.org.mx/temas/imcp/ [acceso: 7 de diciembre de 2020]. 
Pero además se puede plantear como hipótesis otro efecto del aumento al salario mínimo. Según datos del Instituto Nacional de Estadística y Geografía, la población ocupada con ingreso de un solo salario mínimo aumentó en 1978607 personas entre el último trimestre de 2018 y el primero de 2019 , cifra que es $2,75 \%$ más alta que la presentada entre el último trimestre de 2017 y el primer trimestre de 2018, siendo además la cifra más alta en todo el periodo 2016-2019 (único lapso con información disponible). En cambio, la población ocupada con ingresos de más de tres y hasta cinco salarios mínimos disminuyó en 2369062 personas en el último trimestre de 2018 y el primer trimestre de 2019, cifra que representa un golpe de timón, pues en todo el periodo 2016-2018 (a excepción del segundo trimestre de 2017) cada trimestre se había producido un crecimiento en el número de personas ocupadas con este tipo de ingresos ${ }^{12}$. No es posible afirmar la correlación con contundencia — pues no existen investigaciones ni modelos econométricos que lo avalen-, pero es probable que un efecto colateral del aumento al salario mínimo en 2018 sea el incremento de personas en los niveles más bajos de percepción de ingresos, ya sea porque apenas se unieron al mercado laboral o porque disminuyó su remuneración.

Los estudios publicados sobre los efectos del aumento al salario mínimo en 2018 se han concentrado en los cuarenta y tres municipios de la región fronteriza norte, y han incluido en el análisis los estímulos fiscales que decretó el presidente AMLO el 31 de diciembre de $2018^{13}$. En uno de ellos se contrastó el efecto en la inflación y se afirmó que el aumento al salario mínimo y los estímulos fiscales en los municipios de la región fronteriza norte tuvieron un efecto limitado e incluso nulo sobre los precios (Campos y Esquivel, 2020). En un estudio más reciente, también centrado en los municipios de la región fronteriza norte e incluyendo en el análisis los estímulos fiscales, se concluyó que los ingresos laborales aumentaron sustancialmente para los trabajadores, pero sin grandes efectos (positivos o negativos) en los resultados del empleo. Aunque utilizando la variación dentro de los grupos demográficos, se encontró que la elasticidad de la demanda laboral es negativa y significativa para las pequeńas empresas, especialmente para las mujeres (Campos et al., 2020).

En una revisión hemerográfica entre enero y septiembre de 2019, de treinta y nueve artículos recopilados solo seis fueron sobre los posibles efectos negativos del salario mínimo en los municipios de la región fronteriza norte, mientras que cuatro documentaron que las empresas estaban recortando beneficios y bonificaciones para disminuir el impacto del salario mínimo, pero no hubo artículos que documentasen cierres de empresas o contracciones laborales (ibid.).

12. Fuente: Población ocupada según nivel de ingreso, nacional trimestral. Disponible en: https:// www.inegi.org.mx/app/tabulados/default.html?nc=602 [acceso: 28 de febrero de 2020].

13. Véase: «Decreto de Estímulos Fiscales Región Fronteriza Norte». Disponible en: https://dof. gob.mx/nota_detalle.php?codigo $=5547485 \&$ fecha $=31 / 12 / 2018$ [acceso: 8 de diciembre de 2020]. 
El tema del ingreso ha sido nodal para AMLO, como se puede también advertir en el gasto social ${ }^{14}$ durante su primer año de gobierno. En el Presupuesto de Egresos de la Federación de 2019 el gasto en la clasificación funcional de «desarrollo social» ascendió a 2628109,2 millones de pesos, cifra que significa el $63,59 \%$ del gasto programable ${ }^{15}$. Si se mira el promedio de gasto social por periodos presidenciales, en el sexenio de Carlos Salinas de Gortari fue del $48,4 \%$ del total del gasto programable; con Ernesto Zedillo Ponce de León fue de 57,3\%; en el sexenio de Vicente Fox Quesada fue de 59,5\%; durante el de Felipe Calderón Hinojosa fue de 56,3\%, y en el de Enrique Peña Nieto fue de 58,5\%. El porcentaje más alto de gasto social se registró en 2017, con 62,99\%. La cifra de 2019 implica un aumento en términos reales de 931 948,9 millones de pesos con respecto al monto de 2018, de manera que el gasto social en el primer año de gobierno de AMLO representó el más alto registrado en términos reales, porcentuales y respecto de un año previo, sea entre un mismo Gobierno o entre Gobiernos distintos.

Cuadro 2.

Gasto Programable de la función Desarrollo Social, i 988-20i9

\begin{tabular}{cc}
\hline Presidente & Gasto en «desarrollo social» (\% del gasto programable) \\
\hline Carlos Salinas de Gortari & $48,4 \%$ (promedio 1989-1994) \\
\hline Ernesto Zedillo Ponce de León & $57,3 \%$ (promedio 1995-2000) \\
\hline Vicente Fox Quesada & $59,5 \%$ (promedio 2001-2006) \\
\hline Felipe Calderón Hinojosa & $56,3 \%$ (promedio 2007-2012) \\
\hline Enrique Peña Nieto & $58,5 \%$ (promedio 2013-2018) \\
\hline Andrés Manuel López Obrador & $63.59 \%(2019)$ \\
\hline
\end{tabular}

Fuente: elaboración propia a partir de los datos del Centro de Estudios de las Finanzas Públicas de la Cámara de Diputados para el periodo 1990-2011, disponibles en: http://www.cefp.gob.mx/Pub_Gasto_Estadisticas.htm [acceso: 22 de marzo de 2020] y de la Secretaría de Hacienda y Crédito Público para el periodo 2012-2018, disponibles en: http:// presto.hacienda.gob.mx/EstoporLayout/estadisticas.jsp [acceso: 22 de marzo de 2020].

Además del salario mínimo y el gasto social, el Gobierno de AMLO realizó otras modificaciones en cuestiones relevantes de política social, como la denominación, la planeación y la programación. En términos nominativos, modificó el ramo administrativo 20 de «desarrollo social» para denominarlo como «bienestar» (la Secretaría de

14. Entendemos el gasto social como aquel gasto público que se emplea para reducir las brechas de desigualdad y los niveles de pobreza procurando el bienestar social. En el Presupuesto de Egresos de la Federación 2019, la clasificación de gasto en «desarrollo social» incluye: 1) protección social; 2) educación; 3) salud; 4) vivienda y servicios a la comunidad; 5) protección ambiental; 6) recreación, cultura y otras manifestaciones culturales, y 7) otros asuntos sociales.

15. Fuente: Presupuesto de Egresos de la Federación 2019. Análisis funcional económico del gasto programable por destino del gasto. Disponible en: https://cutt.ly/IlmoOpM [acceso: 22 de marzo de 2020]. 
Desarrollo Social —SEDESOL - ahora se denomina Secretaría de Bienestar). Ello parece responder a una estrategia discursiva para tomar distancia de tres décadas de políticas de desarrollo social fallidas (la SEDESOL se creó en 1992, en la presidencia de Salinas de Gortari) para fundar una realidad centrada en los Estados de bienestar, los cuales pueden ser los horizontes de referencia del desarrollo social del presidente.

En términos de planeación, también se evidenciaron cambios con respecto a los Gobiernos predecesores. El 30 de abril de 2019 se publicó el Plan Nacional de Desarrollo 2019-2014 (PND) en la Gaceta Parlamentaria de la Cámara de Diputados, que se caracterizó por dos aspectos medulares. En primer lugar, fue un PND que no estaba unificado, pues se publicaron dos documentos: el identificado como PND 2019-2024 $\left(\right.$ PND 1) ${ }^{16}$ y el identificado como anexos (PND 2) ${ }^{17}$. Como fue constatado por el entonces secretario de Hacienda ${ }^{18}$, quien renunció a su cargo dos meses después, el PND 1 fue redactado por la Presidencia de la república, mientras que el PND 2 fue elaborado por la Secretaría de Hacienda de manera separada, lo cual se percibió hasta en las tipografías. Así, el PND 1 era un documento más de posicionamiento político (cercano a un manifiesto), que no cumplía con los requisitos legales, mientras que el PND 2 sí incluía el diagnóstico, los ejes generales, los objetivos, las estrategias y los indicadores de desempeño, como se asienta en la Ley de Planeación.

Los dos PND no solo eran diferentes, sino incluso contrapuestos en sus planteamientos: el PND 1 atacaba rabiosamente al neoliberalismo, mientras que el PND 2 casi ni lo mencionaba, pero encontraba oportunidades en la globalización; el PND 1 tenía como meta que la tasa de crecimiento económico fuese del $6 \%$ al final del sexenio, mientras que el PND 2 no asentaba ninguna cifra al respecto; el PND 1 afirmaba que en 2024 la pobreza extrema habrá sido erradicada, pero el PND 2 ajustaba la meta a que solo cinco millones de personas dejarían la pobreza extrema. Después de una larga discusión, y en un periodo extraordinario de sesiones, la Cámara de Diputados aprobó el PND 2019-2024 y lo publicó en el Diario Oficial de la Federación el 12 de julio de $2019^{19}$. El plan finalmente aceptado fue el PND 1.

Desde que los planes de desarrollo se instauraron como obligatorios por la Ley de Planeación en 1983, el PND de la 4T es el primer documento con un posicionamiento político claro y contundente, ya que asigna responsabilidades de las crisis económicas y la profundización de la pobreza al «modelo neoliberal», el cual mermó al Estado para «actuar como garante de los derechos fundamentales de los mexicanos»

16. Gaceta Parlamentaria. «Plan Nacional de Desarrollo 2019-2024». Disponible en: https://cutt. ly/BlmaJOk [acceso: 25 de marzo de 2020].

17. Gaceta Parlamentaria. "Anexos». Disponible en: https://cutt.ly/Ulma6Cu [acceso: 25 de marzo de 2020].

18. Columnas «El asunto del Plan Nacional de Desarrollo I» (disponible en: https://cutt.ly/ FzZYhFD) y «El asunto del Plan Nacional de Desarrollo I» (disponible en: https://cutt.ly/ szZYmo6) [acceso: 25 de marzo de 2020].

19. Diario Oficial de la Federación. «Plan Nacional de Desarrollo 2019-2024». Disponible en: https://cutt.ly/61mslLx [acceso: 25 de marzo de 2020]. 
(pp. 6-12). En ese sentido, se aleja por el carril ideológico de los lugares comunes de todos los PND anteriores, donde los diagnósticos se centraban en causas concretas vinculadas a las estrategias y los programas implementados, y no a su fundamento epistemológico. Por ejemplo, en el PND del Gobierno de Enrique Peña Nieto el diagnóstico se centraba en la debilidad institucional, la falta de capital humano y la falta de oportunidades (pp.15-19); es decir, identificaba más consecuencias que causas estructurales.

Una vez identificada «la bancarrota neoliberal», el PND 2019-2024 asume la responsabilidad de construir «una propuesta posneoliberal y de convertirla en un modelo viable de desarrollo económico, ordenamiento político y convivencia entre los sectores sociales», donde el desarrollo no sea "contrario a la justicia social» (p. 8). Para ello, su propuesta se enmarca en doce principios rectores que han sido constantemente enunciados por AMLO: «Honradez y honestidad»; «no al Gobierno rico con pueblo pobre»; «al margen de la ley, nada; por encima de la ley, nadie»; «economía para el bienestar»; «el mercado no sustituye al Estado»; «por el bien de todos, primero los pobres»; "no dejar a nadie atrás, no dejar a nadie fuera»; «no puede haber paz sin justicia»; «el respeto al derecho ajeno es la paz»; «no más migración por hambre o por violencia»; «democracia significa el poder del pueblo», y «ética, libertad, confianza».

El contenido del PND 2019-2024 se divide en tres grandes apartados: 1) política y gobierno; 2) política social, y 3) economía. En el apartado de «Política social» se afirma que el objetivo más importante de la $4 \mathrm{~T}$ es que «en 2024 la población de México esté viviendo en un entorno de bienestar»; para lo cual se requiere de "una fuerte presencia del sector público en la economía, de enérgicas políticas recaudatorias y de una intervención estatal que moderara las enormes desigualdades sociales» (p. 34). Uno de los cambios centrales que se anuncian es que el Estado ya no será gestor de oportunidades, sino garante de derechos (p. 36). En el mismo apartado también se enlistan los programas sociales centrales para la 4T: 1) el Programa para el Bienestar de las Personas Adultas Mayores; 2) Programa Pensión para el Bienestar de las Personas con Discapacidad; 3) Programa Nacional de Becas para el Bienestar Benito Juárez; 4) Jóvenes Construyendo el Futuro; 5) Jóvenes Escribiendo el Futuro; 6) Sembrando Vida; 7) Programa Nacional de Reconstrucción; 8) Desarrollo Urbano y Vivienda, y 9) Tandas para el Bienestar.

Por otra parte, conviene analizar los programas sociales de la 4T, pues evidencian prioridades y enfoques de atención que son distintos de los Gobiernos previos. De hecho, una de las acciones más relevantes del gobierno de AMLO fue la cancelación del emblemático PROSPERA, el programa social de transferencias condicionadas que tenía veintiún años de existencia y que había sido mantenido por cuatro presidentes (Zedillo, Fox, Calderón y Peña), y la transferencia de sus recursos al programa de Becas para el Bienestar Benito Juárez. Si bien ese programa de becas otorga apoyo monetario no condicionado a estudiantes de educación inicial hasta nivel universitario, no ofrece beneficios para la alimentación y la salud como los que proporcionaba el PROSPERA. De esta forma, en los programas sociales de AMLO no existe alguno que seleccione a su población objetivo en los hogares con ingreso inferior a la línea de 
bienestar mínimo, ni que ofrezca beneficios integrales en alimentación, salud y educación para su población beneficiaria.

Según sus programas sociales prioritarios, se puede afirmar que el gobierno de AMLO enfoca sus acciones en a) espacios marginados (el campo y el sur del país) y grupos vulnerables (adultos mayores, jóvenes, personas con discapacidad, pueblos indígenas); b) buscando la inversión productiva (Jóvenes Construyendo el Futuro y Sembrando Vida); c) aumentando los beneficios sociales en modalidad de transferencias monetarias (para que los beneficios lleguen directamente a los ciudadanos), y d) pretendiendo una coordinación intersecretarial para la operación de la política social mediante el término de "programas integrales de desarrollo» (las secretarías de Bienestar, Trabajo y Previsión Social, y Desarrollo Agrario, Territorial y Urbano deben coordinarse para la operación de varios programas sociales).

Sobre el papel, tales enfoques pretenden subsanar fallas estructurales de la política social. No obstante, también conllevan factores que pueden ahondar en sus falencias. Primeramente, aunque se ha afirmado insistentemente que su política social es universal e integral, el gobierno de la 4T en 2019 no realizó modificaciones institucionales para asegurar tales principios, como pueden ser la reorganización del fragmentado Sistema Nacional de Desarrollo Social o la creación de instancias de coordinación intersecretarial o territorial de la política social.

Existen programas que pretenden entregar los mismos montos a los derechohabientes (como las Pensiones Universales) o donde participan varias secretarías (como Jóvenes Construyendo el Futuro), pero al ser solo programas resultan insuficientes como fundamentos de integralidad y universalismo. Es decir, la dispersión y dualidad de los beneficios sociales ${ }^{20}$ se pueden atemperar mínimamente para algunos sectores (adultos mayores, jóvenes, campesinos propietarios) mediante programas sociales, pero al no llevar consigo modificaciones institucionales que subsanen las falencias estructurales, son paliativos sujetos a la cobertura, duración y eficacia de esos programas sociales.

En segundo lugar, tampoco se planteó algún instrumento o espacio para institucionalizar la coordinación de la política social, lo que también se traslada a las delegaciones de Programas para el Desarrollo (nombrados como los «súper delegados estatales»), pues tienen los objetivos prioritarios de «vigilar» los programas sociales y «censar» a los posibles beneficiarios, y no de evitar la dispersión y duplicidad de los programas federales con los estatales y municipales.

20. La estructura de la protección social en México es dual y su acceso es estratificado porque está determinada por la condición laboral y económica de las y los derechohabientes. Esto implica que la disponibilidad de la cartera y la calidad de los beneficios sociales están en función de si las personas tienen empleo formal con salario (remuneraciones altas, medias o mínimas), empleo informal o no tienen empleo. Por lo que se puede afirmar que en la política social mexicana hay «ciudadanías de diverso nivel; es decir, de personas con derechos diferenciados y jerarquizados» (Valencia et al., 2012: 96). 
En tercer lugar, el aumento de los beneficios sociales en la modalidad de transferencias monetarias mejorará sin duda la medición de la pobreza por ingresos, pero es defectuosa como estrategia para la atención de las carencias sociales, tales como el acceso a los servicios de salud o la seguridad social. Es más: utilizar las transferencias monetarias como modalidad principal de los beneficios sociales puede sustituir la responsabilidad estatal de proveer infraestructura, bienes y servicios por la mera entrega de dinero, con lo que incluso se podría dar el caso de que mejore la pobreza por ingresos, pero se mantenga el nivel de las carencias sociales (como la de seguridad social).

Cuadro 3.

Programas Sociales Sin REgLAS DE OPERACIÓN EN EL PRIMER AÑo DEL GOBIERNO DE LA 4 T

\begin{tabular}{|c|c|c|}
\hline Ramo & Programa & Presupuesto \\
\hline $\begin{array}{c}14 \\
\text { (Trabajo y previsión social) }\end{array}$ & Jóvenes Construyendo el Futuro & 40.000 .000 .000 \\
\hline $\begin{array}{c}11 \\
\text { (Educación pública) }\end{array}$ & $\begin{array}{c}\text { Beca Universal para Estudiantes de } \\
\text { Educación Media Superior Benito Juárez }\end{array}$ & 17.280 .000 .000 \\
\hline $\begin{array}{c}20 \\
\text { (Bienestar) }\end{array}$ & Sembrando Vida & 15.000 .000 .000 \\
\hline $\begin{array}{c}08 \\
\text { (Agricultura y desarrollo rural) }\end{array}$ & Producción para el Bienestar & 9.000 .000 .000 \\
\hline $\begin{array}{c}20 \\
(\text { Bienestar })\end{array}$ & $\begin{array}{l}\text { Pensión para el Bienestar de las } \\
\text { Personas con Discapacidad Permanente }\end{array}$ & 8.500 .000 .000 \\
\hline $\begin{array}{c}08 \\
\text { (Agricultura y desarrollo rural) }\end{array}$ & Desarrollo Rural & 7.831 .553 .872 \\
\hline $\begin{array}{c}08 \\
\text { (Agricultura y desarrollo rural) }\end{array}$ & Agromercados Sociales y Sustentables & 6.707 .734 .811 \\
\hline $\begin{array}{c}08 \\
\text { (Agricultura y desarrollo rural) }\end{array}$ & $\begin{array}{c}\text { Precios de Garantía a Productos } \\
\text { Alimentarios Básicos }\end{array}$ & 6.000 .000 .000 \\
\hline $\begin{array}{c}08 \\
\text { (Agricultura y desarrollo rural) }\end{array}$ & Crédito Ganadero a la Palabra & 4.000 .000 .000 \\
\hline $\begin{array}{c}10 \\
(\text { Economía })\end{array}$ & $\begin{array}{c}\text { Programa de Microcréditos para el } \\
\text { Bienestar }\end{array}$ & 3.033 .233 .942 \\
\hline $\begin{array}{c}08 \\
\text { (Agricultura y desarrollo rural) }\end{array}$ & Fertilizantes & 1.500 .000 .000 \\
\hline $\begin{array}{c}11 \\
\text { (Educación pública) }\end{array}$ & $\begin{array}{c}\text { Universidades para el Bienestar Benito } \\
\text { Juárez García }\end{array}$ & $\$ 1.000 .000 .000$ \\
\hline Total & & 119.852 .522 .625 \\
\hline
\end{tabular}

Fuente: elaboración propia según los datos del Catálogo de Programas Presupuestarios del Presupuesto de Egresos de la Federación 2019, Secretaría de Hacienda y Crédito Público. Disponible en: https://www.pef.hacienda.gob.mx/es/ PEF2019/analiticos_presupuestarios [acceso: el 23 de marzo 2020]. 
En cuarto lugar, existen programas sociales prioritarios para el Gobierno federal que fueron presupuestados como "otros subsidios", es decir, que no estuvieron sujetos a reglas de operación y, al no ajustarse a los postulados de la Ley Federal de Presupuesto y Responsabilidad Hacendaria, su manejo puede ser más laxo en términos de seguimiento, evaluación, control y fiscalización. Fueron, por tanto, programas que pueden tender a la discrecionalidad, la opacidad y la manipulación en el monitoreo y evaluación de sus objetivos. El monto total de estos programas sociales en 2019 (entre los que se encuentran Jóvenes Construyendo el Futuro, Sembrando Vida y Pensión para Personas con Discapacidad) ascendió a 119852522625 pesos.

El presupuesto de estos programas conduce, por último, a apuntar el tema de la opacidad y sus posibles consecuencias, pues más allá de declaraciones presidenciales anunciando «el fin de la corrupción», el Gobierno de la 4T no ha especificado los mecanismos o instancias que utilizará para blindar sus programas de usos clientelares, lo que ha sido una práctica sistemática en otras Administraciones y que el presidente AMLO prometió erradicar.

De esta forma, en el primer año de gobierno de la $4 \mathrm{~T}$ hubo renombramientos de instituciones, dos planes de desarrollo nacionales, programas sociales prioritarios, cambios en las modalidades de beneficios sociales e incluso un aumento del gasto social y de los ingresos vía el salario mínimo. Más allá de su coherencia interna, ¿cómo de relevantes pueden ser esas acciones para convertir a la política social del Gobierno federal mexicano en una herramienta eficaz para combatir la pobreza y proveer bienestar? Ello se analiza en el último apartado de este documento.

\section{EVALUACIÓN DEL PRIMER AÑO DE LA POLÍTICA SOCIAL DE LA 4T}

Hace décadas que AMLO venía insistiendo que en México debería existir justicia social, para lo cual deben estar "primero los pobres». Ya como presidente de la república, su diagnóstico sobre el desarrollo social —asentado en el PND 1-atribuyó las causas de los bajos niveles de bienestar y los altos índices de pobreza al neoliberalismo y las políticas implementadas en las últimas tres décadas. En razón a ello, propuso una gestión pública basada en los principios rectores de la honestidad, la austeridad y la justicia social, lo que permitiría al Estado mexicano retomar la rectoría del desarrollo y convertirse así en un genuino Estado de bienestar.

Para ir concretando su estrategia de desarrollo, en su primer año centró sus esfuerzos en tres ejes: a) el aumento de recursos vía gasto social y salario mínimo; b) la proliferación de programas sociales de transferencias monetarias, que c) priorizan su atención en espacios marginados y grupos vulnerables. Todas esas estrategias, programas y acciones han sido diseńadas e implementadas mediante una inercia proveniente de la autoridad y legitimidad presidencial, lo que puede explicar su poca atención a ejes constitutivos de una gestión pública racional y transparente. Esta situación queda patente en que la mayoría de sus programas sociales prioritarios fueron presupuestados para no estar sujetos a reglas de operación. 
Si la propuesta de transformación en el PND 2019-2024 pretende ser de cambio estructural en el régimen de política social, las estrategias, recursos y acciones deben ser consecuentes con dicha enunciación. Sin embargo, aunque se registran planteamientos destacados (centralidad de los derechos sociales, prioridad de atención a grupos vulnerables, efectividad en el recibimiento de las ayudas sociales para los beneficiarios), estos parecen haber resultado insuficientes para llevar a cabo la gran transformación anunciada, pues más allá de programas sociales prioritarios no se mencionan estrategias, instituciones o acciones para asegurar la universalidad de la protección social, ampliar la cobertura y calidad de los servicios sociales, o para afrontar la dispersión segmentación, duplicidad, ineficiencia institucional de los estados o el clientelismo político; es decir, los grandes fallos estructurales del régimen de política social mexicano.

Es injusto políticamente, e incluso académicamente inválido, establecer un juicio definitivo sobre un Gobierno considerando solo una sexta parte de su periodo de vigencia; sin embargo, se pueden establecer algunas proyecciones. He aquí la principal sobre su política social: el gobierno de la $4 \mathrm{~T}$ dependerá de la voluntad y legitimidad presidencial para la construcción de su visión de bienestar, lo que puede derivar no en la construcción de un Estado de bienestar (un entramado institucional integrado con un sistema de protección social universal, coherente e integral), sino, como lo definió María Amparo Casar, de la figura del Gran Benefactor (los beneficios sociales asociados a la filantropía de un presidente benevolente) ${ }^{21}$. Ello, obviamente, no subsana las falencias estructurales del régimen de política social mexicano, sino que incluso puede profundizar aún más una de sus mayores tergiversaciones: su uso como instrumento de clientelismo político.

En el momento de redactar estas conclusiones, el gobierno de AMLO estaba por cumplir su segundo año de funciones. El año 2020 sobrepasa el periodo de tiempo establecido en este artículo como objetivo analítico, pero vale la pena dar cuenta de dos hechos. En primer lugar, la contingencia sanitaria provocada por la pandemia del virus SARS-CoV-2 (COVID-19) ha tenido impactos severos en México, hasta el punto de que el CONEVAL calculó que la población en situación de pobreza extrema podría aumentar hasta en 10,7 millones (llegando a las 31,7 millones de personas) y la población pobre podría incrementarse hasta en 9,8 millones (llegando a un total 61,1 millones de personas) (CONEVAL, 2020: 37).

Para atender los efectos de la pandemia, el presidente anunció un plan emergente para el bienestar y once medidas para enfrentar dicha crisis. En términos de política social, anunció la intensificación de sus programas sociales (proyectando que cubriesen a veintidós millones de beneficiarios) y el otorgamiento de tres millones de créditos a la población más necesitada ${ }^{22}$. En suma, los apoyos anunciados por AMLO llegarían

21. «El Gran Benefactor». Disponible en: https://www.nexos.com.mx/?p=41305 [acceso: 28 de marzo de 2020].

22. «Discurso del presidente Andrés Manuel López Obrador al pueblo de México». Disponible en: https://cutt.ly/zlmzcG0 [acceso: 20 de octubre de 2020]. 
a veinticinco millones de personas (veintisiete millones si se acepta como válida su medida de crear dos millones de empleos), pero tales medidas parecen insuficientes si se toman en cuenta las proyecciones del CONEVAL, según las cuales quedarían desprotegidas 34,1 millones de personas con ingresos inferiores al umbral de pobreza. A diferencia de lo sucedido en otros países latinoamericanos, en México no se creó ninguna transferencia monetaria de emergencia para la población vulnerable.

En segundo lugar, el 8 de mayo de 2020 se reformó el artículo $4 .^{\circ}$ constitucional para asentar que toda persona tiene derecho a la salud y que el Estado garantizará la entrega de apoyos a personas con discapacidad, una pensión no contributiva a las personas mayores de sesenta y ocho ańos, y un sistema de becas para las y los estudiantes de todos los niveles educativos ${ }^{23}$.

Aunque dicha reforma ha sido valorada por el presidente como «una gran reforma, histórica, porque eleva a rango constitucional estos derechos, es ir hacia el Estado de bienestar» ${ }^{24}$, es un cambio jurídico importante en el que se perdió la oportunidad de elevar a rango constitucional la obligatoriedad de un sistema de protección social universal, pues tan solo se reconoció el esquema de prioridades de la política social de AMLO: las transferencias monetarias a los grupos vulnerables que el presidente atiende con sus programas sociales (personas con discapacidad, adultos mayores y estudiantes).

Como se ha expuesto en este artículo, el Gobierno de la $4 \mathrm{~T}$ ha realizado cambios destacados para combatir la pobreza y procurar el bienestar social, pero hasta el momento han resultado insuficientes para hacer una transformación radical de la política social en México, pues no subsanan —e incluso ahondan en temas como el clientelismo - las falencias estructurales del régimen de política social. Lo comentado sobre el año 2020 permite mantener abierta esta línea de investigación.

\section{Referencias}

Antía, Florencia. 2018. «Regímenes de política social en América Latina: una revisión crítica de la literatura», Desafíos, 30 (2): 193-235. Disponible en: https://doi. org/10.12804/revistas.urosario.edu.co/desafios/a.4802.

Banerjee, Abhijit y Esther Duflo. 2014. Repensar la pobreza. Un giro radical en la lucha contra la desigualdad global. Buenos Aires: Santillana.

Barba Solano, Carlos. 2007. ¿Reducir la pobreza o construir ciudadanía social para todos? América Latina: regímenes de bienestar en transición al iniciar el siglo XXI.

23. «Decreto por el que se reforma y adiciona el artículo 4. ${ }^{\circ}$ de la Constitución Política de los Estados Unidos Mexicano». Diario Oficial de la Federación, 8 de mayo de 2020. Disponible en: https://cutt.ly/1lmzG8I [acceso: 22 de octubre de 2020].

24. «Histórica reforma al artículo 4. ${ }^{\circ}$ constitucional, afirma el presidente; convoca a personal médico para atender COVID-19». Presidencia de la República. Disponible en: https://cutt.ly/ flmz3dC [acceso: 21 de febrero de 2021]. 
México: Universidad de Guadalajara. Disponible en: https://doi.org/10.1590/ S0103-49792007000200002.

Barba Solano, Carlos. 2016. «Las propuestas de reformas y las nuevas estrategias sociales del gobierno de Enrique Peña Nieto: ¿cambio de rumbo en la política social mexicana?», en Enrique Valencia Lomelí y Gerardo Ordóńez Barba (coords.), Nueva ronda de reformas estructurales en México. ¿Nuevas políticas sociales? Tijuana: El Colegio de la Frontera Norte.

Bizberg, Ilán. 2012. «El régimen de bienestar mexicano, del corporativismo al asistencialismo", en Ilán Bizberg y Martin Scott. El Estado de bienestar ante la globalización, el caso de Norteamérica, México. Ciudad de México: El Colegio de México.

Brachet-Márquez, Viviane. 1996. El pacto de dominación: Estado, clase y reforma social en México (1910-1995). México: El Colegio de México.

Campos, Raymundo, Víctor Delgado y Eduardo Medina. 2018. «La política social en México: geografía, alcances y cambios posibles». México: CONEVAL. Disponible en: https://cutt.ly/klmv1C6.

Campos, Raymundo, Víctor Delgado y Alexis Rodas. 2020. «The effects of placebased tax cut and minimum wage increase on labor market outcomes», IZA Journal of Labor Policy, 10 (1): 1-24. Disponible en: https://doi.org/10.2478/izajolp2020-0012.

Campos, Raymundo y Gerardo Esquivel. 2020. «The effect of doubling the minimum wage and decreasing taxes on inflation in Mexico", Economics Letters, 189: 1-4. Disponible en: https://doi.org/10.1016/j.econlet.2020.109051.

Castillo Fernández, Dídimo y Jorge Arzate Salgado. 2013. «Crisis económica, pobreza y política social en México", Aportes, Revista de la Facultad de Economía, 18 (47): 57-82.

Cejudo, Guillermo y Cynthia Míchel. 2015. «Resolviendo problemas sociales complejos mediante la integración de políticas. El caso de la Cruzada Nacional contra el Hambre en México", Revista del CLAD Reforma y Democracia, 63: 33-64.

CONEVAL, Consejo Nacional de Evaluación de la Política de Desarrollo Social. 2009. Evolución de la pobreza en México. México: CONEVAL.

CONEVAL, Consejo Nacional de Evaluación de la Política de Desarrollo Social. 2010. «Lineamientos y criterios generales para la definición, identificación y medición de la pobreza». Diario Oficial de la Federación, 19 de mayo de 2010.

CONEVAL, Consejo Nacional de Evaluación de la Política de Desarrollo Social. 2016. Informe de evaluación de la politica de desarrollo social 2016. México: CONEVAL.

CONEVAL, Consejo Nacional de Evaluación de la Política de Desarrollo Social. 2017a. ¿Qué resultados buscan lograr los programas sociales en México? Informe de enfoque de resultados 2017. México: CONEVAL.

CONEVAL, Consejo Nacional de Evaluación de la Política de Desarrollo Social. 2017b. Presentación y análisis del Inventario federal de programas y acciones de desarrollo social 2016-2017. México: CONEVAL.

CONEVAL, Consejo Nacional de Evaluación de la Política de Desarrollo Social. 2018a. Consideraciones para el proceso presupuestario 2019. México: CONEVAL. 
CONEVAL, Consejo Nacional de Evaluación de la Política de Desarrollo Social. 2018b. Informe de evaluación de la politica de desarrollo social 2018. México: CONEVAL.

CONEVAL, Consejo Nacional de Evaluación de la Política de Desarrollo Social. 2019a. Diez años de medición de pobreza multidimensional en México: avances y desafios en politica social Medición de la Pobreza serie 2008-2018. México: CONEVAL.

CONEVAL, Consejo Nacional de Evaluación de la Política de Desarrollo Social. 2019b. Análisis de los programas sociales del PEF 2018 y 2019. México: CONEVAL.

CONEVAL, Consejo Nacional de Evaluación de la Política de Desarrollo Social. 2020. La politica social en el contexto de la pandemia por el virus SARS-CoV-2 (COVID-19) en México. México: CONEVAL.

Dautrey, Philippe. 2013. «Precariedad de la sociedad, segmentación de la política social: el caso de México", Revista Europea de Estudios Latinoamericanos y del Caribe, 94: 25-42.

EVALÚA, Consejo de Evaluación del Desarrollo Social de la Ciudad de México. 2019. Medición de la pobreza en la Ciudad de México. México: EVALÚA. Disponible en: https://cutt.ly/LlmbMRR.

Gabarrot Arenas, Mariana. 2012. «Algunas contradicciones en la política social mexicana. Bienestar y combate a la pobreza», Trace. Travaux et Recherches dans les Amériques du Centre, 62: 36-49. Disponible en: https://doi.org/10.22134/trace.62.2012.457.

GESOC, Gestión Social y Cooperación A. C. 2017. Indice de desempeño de los programas públicos federales, (INDEP). México: GESOC. Disponible en: https:// cutt.ly/HlmnezI.

Herrera Gómez, Manuel y Pedro Castón Boyer. 2003. Las politicas sociales en las sociedades complejas. Barcelona: Ariel.

Hevia de la Jara, Felipe. 2010. «Uso político de programas sociales y nuevos intermediarios institucionales: el Programa Progresa/Oportunidades en el Sur de Veracruz», Desacatos, 34: 119-132.

IPRO, Iniciativa para el Fortalecimiento de la Institucionalidad de los Programas Sociales. 2018. Informe de resultados 2018. México: Transparencia Mexicana; PNUD.

Martínez Espinoza, Manuel. 2019. Políticas sociales y participación en México. El caso del programa Comedores Comunitarios. México: UNICACH; Miguel Ángel Porrúa.

Martínez Franzoni, Juliana. 2008. ¿Arañando bienestar? Trabajo remunerado, protección social y familias en América Central. Buenos Aires: CLACSO.

Molina Cano, Jerónimo. 2004. La politica social en la historia. Murcia: Isabor.

Montagut, Teresa. 2000. Politica social: una introducción. Barcelona: Ariel.

Moreno Salazar, Pedro, Claudia Ortiz Guerrero y Eduardo Marrufo Heredia. 2004. "Veinticinco años de desarrollo social en México», Sociológica, 19 (54): 55-75.

Ordóñez Barba, Gerardo. 2017. El Estado social en México. Un siglo de reformas hacia un sistema de bienestar excluyente. Tijuana: El Colegio de la Frontera Norte; Siglo XXI.

Ordónez Barba, Gerardo. 2018. «La lucha contra la pobreza en México en las últimas tres décadas. Alcances y limitaciones», en Carmen Midaglia. Gerardo Ordóńez y Enrique Valencia (coords.), Políticas sociales en América Latina en los inicios del 
siglo XXI: innovaciones, inercias y retrocesos. Buenos Aires: CLACSO; Tijuana: El COLEF. Disponible en: https://doi.org/10.2307/j.ctvn96gmn.17.

Ordóñez Barba, Gerardo y Aída Silva Hernández. 2019. «Progresa-oportunidades-Prospera: avatares, alcances y resultados de un programa paradigmático contra la pobreza", Papeles de Población, 25 (99): 77-111.

PNUD, Programa de las Naciones Unidas para el Desarrollo. 2019. Informe de Desarrollo Humano Municipal 2010-2015. México: PNUD.

Pribble, Jennifer. 2011. "Worlds Appart: Social Policy Regimes in Latin America», Studies in Comparative International Development, 46: 191-216. Disponible en: https://doi.org/10.1007/s12116-010-9076-6.

Rodríguez, Juan Carlos y Jonathan Nácar. 2018. «Los programas duplicados cuestan \$2.4 billones», Eje central, 27 de julio de 2018. Disponible en: https://cutt.ly/81$\mathrm{mmi} 4 \mathrm{~m}$.

Spicker, Paul. 2009. "Definiciones de pobreza: doce grupos de significados», en Paul Spicker, Sonia Álvarez y David Gordon (eds.), Pobreza: un glosario internacional. Buenos Aires: CLACSO.

Székely, Miguel. 2005. Pobreza y desigualdad en México entre 1950 y el 2004. Documentos de investigación, 24. México: SEDESOL.

Titmuss, Richard. 1981. Politica social. Barcelona: Ariel.

Torres, Felipe y Agustín Rojas. 2015. «Política económica y política social en México: desequilibrios y saldos», Problemas del Desarrollo. Revista Latinoamericana de Economía, 46 (182): 41-66. Disponible en: https://doi.org/10.1016/j.rpd.2015.06.001.

Valencia Lomelí, Enrique, David Foust Rodríguez y Darcy Tetreault Weber. 2012. Sistema de protección social en México a inicios del siglo XXI. Santiago: CEPAL.

Valverde Viesca, Karla. 2015. Construcción institucional del desarrollo social en México. Ciudad de México: UNAM.

Presentado para evaluación: 31 de marzo de 2020.

Aceptado para publicación: 30 de diciembre de 2020.

\section{MANUEL I. MARTÍNEZ ESPINOZA}

manuel.martinez.espinoza@gmail.com; mimartinezes@conacyt.mx

ORCID ID: https://orcid.org/0000-0002-8766-3530

Doctor en Procesos Políticos Contemporáneos por la Universidad de Salamanca, catedrático del Consejo Nacional de Ciencia y Tecnología (CONACYT), comisionado en el Centro de Estudios Superiores de México y Centroamérica de la Universidad de Ciencias y Artes de Chiapas (CESMECA-UNICACH), donde investiga sobre los regímenes de política social en el sur de México y Centroamérica. Ha publicado dos libros como autor único y una veintena de artículos en revistas indizadas nacionales e internacionales. Es miembro del Sistema Nacional de Investigadores (nivel I) del CONACYT y evaluador del Sistema Nacional de Evaluación Científica y Tecnológica del CONACYT. 